\title{
Development of an Animal Model to Evaluate the Allergenicity of Food Allergens
}

\author{
Birgit Ahrens $^{a}$ David Quarcoo ${ }^{a, c}$ Sabine Buhner ${ }^{b, d}$ Gerald Reese ${ }^{f}$ \\ Stefan Vieths ${ }^{f}$ Eckard Hamelmann ${ }^{a, e}$ \\ Departments of a Pediatric Pneumology and Immunology, ${ }^{b}$ Gastroenterology and ${ }^{\mathrm{C}}$ Institute of Occupational

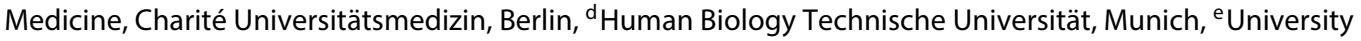 \\ Children's Hospital, Ruhr University, Bochum, and f Paul-Ehrlich-Institut, Division of Allergology, Langen, Germany
}

\section{Key Words}

Food allergy · Immunological responses .

Permeability index

\begin{abstract}
Scope: Considering the increasing numbers of patients suffering from food allergy (FA) as well as the great variety of novel foods and food compositions, an unmet need exists for the development of preclinical approaches to characterize the allergenic potential of proteins. The aim of our study was to evaluate the allergenicity of different food allergens in a rat model. Methods: Brown Norway rats were sensitized to protein extracts (RuBisCO, apple, soy, peanut, garden pea) or ovalbumin (OVA) combined with Bordetella pertussis and aluminium hydroxide, followed by oral allergen challenges. Results: Allergen-specific serum immunoglobulin production and the proliferation of mononuclear cells from spleen confirmed sensitization. To assess functional alterations in the gut, intestinal permeability was measured, which increased in sensitized and challenged animals compared to non-sensitized controls. Allergens with high allergenic po-
\end{abstract}

\section{KARGER}

E-Mail karger@karger.com www.karger.com/iaa tential (peanut, OVA, soy) caused a stronger immunological response than allergens with low allergenic potential, such as RuBisCO and apple. Moreover, the immunological responses were reduced when using boiled instead of raw soy and pea proteins. Conclusion: This model mimics key features of FA and facilitates investigating the allergenicity of allergens in novel food or food compositions in vivo.

(c) 2014 S. Karger AG, Basel

\section{Introduction}

Food allergy (FA) is an important health issue in westernized countries, with around $8 \%$ of children and $5 \%$ of adults affected [1]. Although any food protein can possibly act as an allergen, relatively few protein families cause the majority of allergic reactions [2]. Foods with the highest number of published reports are cow's milk, hen's egg, peanut, fish and shellfish [3]. The severity of reactions elicited by these food allergens may vary substantially, ranging from fatal reactions mostly observed in regards to peanut allergy [4] to milder responses detected
(C) 2014 S. Karger AG, Basel

$1018-2438 / 14 / 1642-0089 \$ 39.50 / 0$
Correspondence to: Prof. Eckard Hamelmann

University Children's Hospital, Ruhr University

Alexandrinenstrasse 5

DE-44791 Bochum (Germany)

E-Mail eckard.hamelmann@rub.de 
in, for example, soybean- or apple-allergic patients [5-7]. The particular allergenicity of a food allergen is not only determined by its source, but also relies on the condition and the state of processing (cooked, boiled, roasted, etc.) of the food products [8]. Interestingly, although the epitopes of many known allergens have yet to be identified, there seems to be no clear structural or other property common to all food allergens allowing the reliable prediction of their allergenicity [9].

Considering the overall prevalence of FA [1] and the rising accessibility of novel foods and or food compositions, for example from transgenic crop plants, there is a growing need for the development of preclinical approaches that may help to characterize the allergenic potentials of proteins and to predict their risk of initiating severe anaphylactic reactions [9]. The example of the introduction of lupine flour (Lupinus albus), a member of the legume family, to a variety of foods nearly 2 decades ago showed how important a careful selection in advance would have been. Lupine was supplied for food manufacturing for its textural properties in bakery products [10]. Unfortunately, lupine allergy develops by cross-reactivity in patients who are already sensitized to other members of the legume family, in particular peanut, soy or pea [10]. As allergic reactions to lupine became more and more frequent, lupine was added to the list of commonly allergenic foods in the EU 10 years after its introduction (Annex IIIa; directive 2000/13/EC).

Currently, the strategy for assessing the potential allergenicity of (genetically engineered) food is based on guidelines from the European Food Safety Authority (EFSA) and the Food and Agriculture Organization (FAO)/World Health Organization (WHO) [11-13]. A weight of evidence approach includes comparing the introduced protein with known allergens based on gene source, sequence homology and, if necessary, reactivity with serum from allergic patients, as well as evaluating the protein's stability against digestive enzymes [14].

Animal models have played a valuable role in increasing our understanding of the immunology and pathology involved in allergic responses to food proteins $[15,16]$. Oral sensitization with food allergens in genetically apt rodents has resulted in the production of allergen-specific IgE and various phenotypical changes that mimicked the disease in human FA patients [17]. However, most of these studies did not assess responses in the gastrointestinal tract upon local (oral) allergen provocation and, therefore, missed a cardinal feature of the human disease. In the current study, we utilized our established rat model of FA [18] to associate immune responses and pheno- typical changes after sensitization with oral allergen challenges in order to better delineate the allergic potential of different common food allergens.

\section{Material and Methods}

\section{Animals}

All experiments were approved by the animal research ethical institution, LAGetSi (Berlin, Germany). Male Brown Norway (BN) rats, aged 6-8 weeks, weighing 180-230 g (BfR, Berlin, Germany) and maintained on a peanut-, ovalbumin (OVA)-, apple-, pea- and soybean-free diet, arrived pathogen-free and were kept under controlled conditions.

\section{Sensitization and Treatment}

Animals were sensitized by intraperitoneal (i.p.) injections on days 1,5 and 10 with the following food allergens adsorbed on aluminium hydroxide: $10 \mu \mathrm{g}$ of OVA (main egg white protein, as the reference allergen), $2.5 \mu \mathrm{g}$ of RuBisCO (ribulose-1,5-biphosphate carboxylase/oxygenase, a protein in green plants and the main abundant protein on earth), $2.5 \mu \mathrm{g}$ of apple (extracted protein), $2.5 \mu \mathrm{g}$ of green garden pea (protein extract from raw and/or boiled pea), $2.5 \mu \mathrm{g}$ of soy (protein extract from raw and/or boiled soy) and $2.5 \mu \mathrm{g}$ of peanut (protein extract from roasted peanut). The protein extract preparation has been described in detail previously [19]. In addition to the first allergen injection, animals were given a booster with a single i.p. injection of Bordetella pertussis whole-body vaccine $\left(2 \times 10^{6}\right)$.

Sensitized animals were challenged by gavage feeding with the following allergens on days 20 and 21: $100 \mu \mathrm{g}$ of OVA (in $1 \mathrm{ml}$ of PBS), $1 \mathrm{mg}$ of RuBisCO, $1 \mathrm{mg}$ of apple extract protein, $1 \mathrm{mg}$ of soybean extract protein, $1 \mathrm{mg}$ of pea extract protein and $1 \mathrm{mg}$ of peanut extract protein. Animals of the negative control groups were sham-sensitized and challenged with PBS according to the same protocols. All animals were sacrificed and analyzed $24 \mathrm{~h}$ after the last allergen challenge, on day 22 (fig. 1).

\section{Assessment of Immunoglobulin Levels}

Serum antibody levels of total IgE and allergen-specific IgE and IgG were measured by enzyme-linked immunosorbent assay (ELISA) as previously described [20]. Briefly, mircrotiter plates coated with monoclonal anti-rat IgE antibody were incubated with diluted serum samples and biotinylated allergen, and streptavidinperoxidase was used as a substrate. For biotinylation of RuBisCO, apple extract, pea extract, soybean extract, peanut extract and OVA, the biotinylation kit of Sigma ${ }^{\circledR}$ (Sigma, Deisenhofen, Germany) was used according to the manufacture's instructions. For quantification of specific IgE-serum levels, in-house controls were utilized, thus allowing no direct comparison between specific IgE levels against different allergens.

\section{Cell Culture}

Spleen and mesenteric lymph node mononuclear cells were purified by density gradient centrifugation (Lympholyte Rat; Cedarlane Laboratories, Hornby, Ont., Canada; 1,000 g, $20 \mathrm{~min}$ at room temperature) and suspended in RPMI 1640 containing 10\% FCS (Biochrome, Berlin, Germany) for proliferation assays and cytokine production.
Ahrens/Quarcoo/Buhner/Reese/Vieths/ Hamelmann 
Fig. 1. Treatment protocol: $\mathrm{BN}$ rats were sensitized to different allergens i.p. on days 1,5 and 10 . The negative control group was sham-sensitized with PBS. The animals were challenged by gavage feeding of specific allergen extracts on days 20 and 21 . Control animals received only PBS p.o. The $\mathrm{BN}$ rats were analyzed $24 \mathrm{~h}$ after the last challenge, on day 22 .

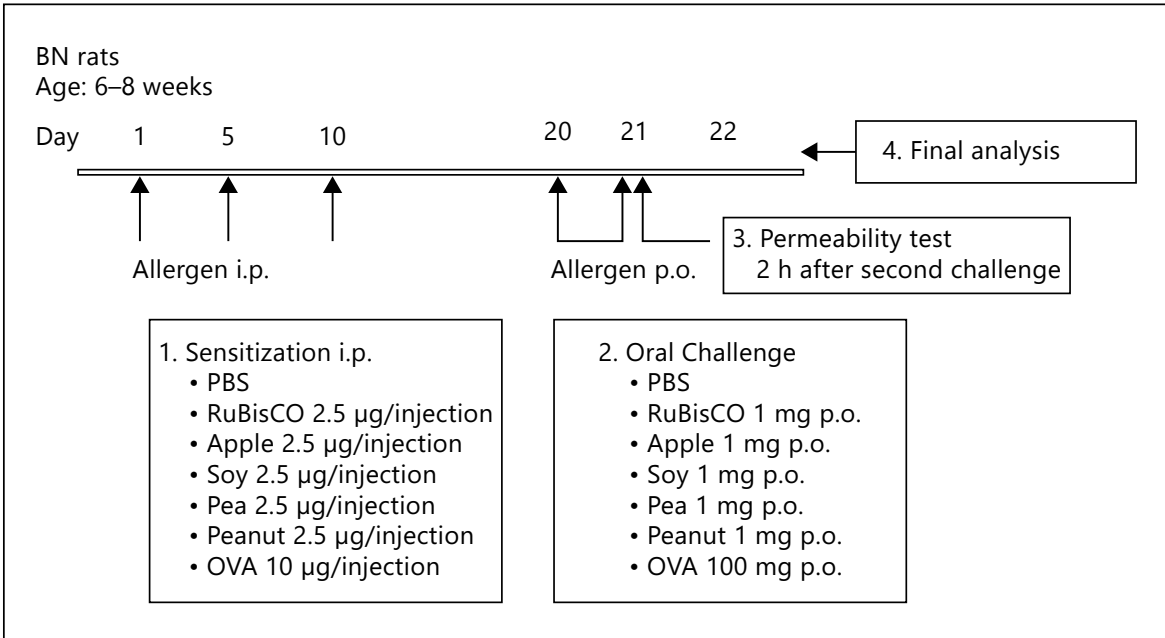

\section{Proliferative Responses}

Mononuclear cells $\left(3 \times 10^{5} /\right.$ well $)$ were incubated in 96-well Ubottomed tissue-culture plates (Costar, Cambridge, Mass., USA) at $37^{\circ} \mathrm{C}$ and $5 \% \mathrm{CO}_{2}$, and stimulated for $96 \mathrm{~h}$ with mitogen (Concanavalin A, $2.5 \mu \mathrm{g} / \mathrm{ml}$, Sigma) or allergen (100 $\mu \mathrm{g} / \mathrm{ml}$ of OVA, Sigma; $100 \mu \mathrm{g} / \mathrm{ml}$ of RuBisCO, and $100 \mu \mathrm{g} / \mathrm{ml}$ of protein extracts from, apple, pea, soy, peanut). 3[H]-thymidine (Amershan Buchler, Braunschweig, Germany) was added for the last $18 \mathrm{~h}$ of the cell culture $(1 \mu \mathrm{Ci} /$ well $)$, and thymidine uptake was measured in a liquid scintillation counter (Wallac, Väsby, Sweden). The proliferation rate was calculated as multiples of $3[\mathrm{H}]$-thymidine incorporation by stimulated cells compared to that of non-stimulated cells.

\section{Intestinal Permeability}

Intestinal permeability was assessed using a sugar-recovery test as previously described and reported in detail [18]. The test is based on the measurement of the urinary excretion of orally (p.o.) administered non-metabolized sugar probe molecules. Lactulose and mannitol have been demonstrated to meet the criteria for usage as tracers [21]. Two hours after the second allergen challenge, the animals received $2 \mathrm{ml}$ of $\mathrm{PBS}$ by oral route, containing lactulose $(10 \mathrm{mg})$ and mannitol $(5 \mathrm{mg})$, followed $2 \mathrm{~h}$ later by $2 \mathrm{ml}$ of drinking water. The tracers recovered in the first $8 \mathrm{~h}$ in the urine were detected and quantified by high-performance liquid chromatography (HPLC), with pulsed electrochemical detection (Dionex, Idstein, Germany), chromatography module $250 \times 40 \mathrm{~mm}$ Carbopac PA-1 column (Dionex), eluent $150 \mathrm{mmol} \mathrm{NaOH}$ and flow $1 \mathrm{ml} /$ min [21]. Results were expressed as the percentage recovery of the ingested dose of the sugars. The ratio of recovered lactulose and mannitol (permeability index) served as a marker for intestinal permeability.

\section{Statistical Analysis}

Calculations were performed with the statistical software SPSS (SPSS Inc., Chicago, Ill., USA) and R (R Foundation for Statistical Computing, Vienna, Austria). Graphs were generated in GraphPad Prism (version 4; GraphPad Software Inc., San Diego, Calif., USA) and R. We performed the non-parametric two-sample Wilcoxon test (Mann-Whitney test) and pvalues $<0.05$ were regarded as significant.

\section{Results}

\section{Immunoglobulin Production after Allergen Sensitization}

In order to analyze the sensitization status of $\mathrm{BN}$ rats, total and specific IgE serum levels were measured before ('naive'; fig. 2) and after allergen sensitization and oral challenges (day 17; fig. $2 \mathrm{a}$ ). In naive $\mathrm{BN}$ rats, total IgE averaged $534 \pm 273 \mathrm{ng} / \mathrm{ml}$. After sensitization with the different allergens, a significant increase of total IgE in each group was detected, showing the expected allergic immune response. The strongest increase was measured after sensitization with members of the legume family: raw pea $(7,932 \pm 4,978 \mathrm{ng} / \mathrm{ml})$, raw soy $(11,206 \pm 8,727 \mathrm{ng} / \mathrm{ml})$ and peanut $(12,471 \pm 7,936 \mathrm{ng} / \mathrm{ml})$.

Allergen-specific IgE was detected by ELISA. A significant increase of specific IgE was detected after soybean, OVA and peanut sensitization. There was no significant increase of allergen-specific IgE after sensitization with pea; administration of extract of raw and boiled pea did not induce significant increases of pea-specific IgE (fig. 2b).

\section{Proliferative Response of Mononuclear Cells}

Spleen mononuclear cells from allergen-sensitized and challenged $\mathrm{BN}$ rats were stimulated in vitro with the respective allergen to measure allergen-specific proliferative responses. We detected significantly enhanced responses compared to cells from non-sensitized controls after sensitization with raw pea, raw soybean, peanut and OVA (fig. 3). No significant increase was detected after sensitization with RuBisCO, apple, and extracts of boiled pea and soybeans. 
Fig. 2. Immunoglobulin levels in allergensensitized and challenged $\mathrm{BN}$ rats: total $\operatorname{IgE}$ (a), specific IgE (b). BN rats were treated as described in figure 1. On day 1 (before sensitization, 'naive') and on day 22 , immunoglobulin levels in the serum of the animals were measured. Animals of the control groups were sham-sensitized and challenged with PBS according to the same protocols.

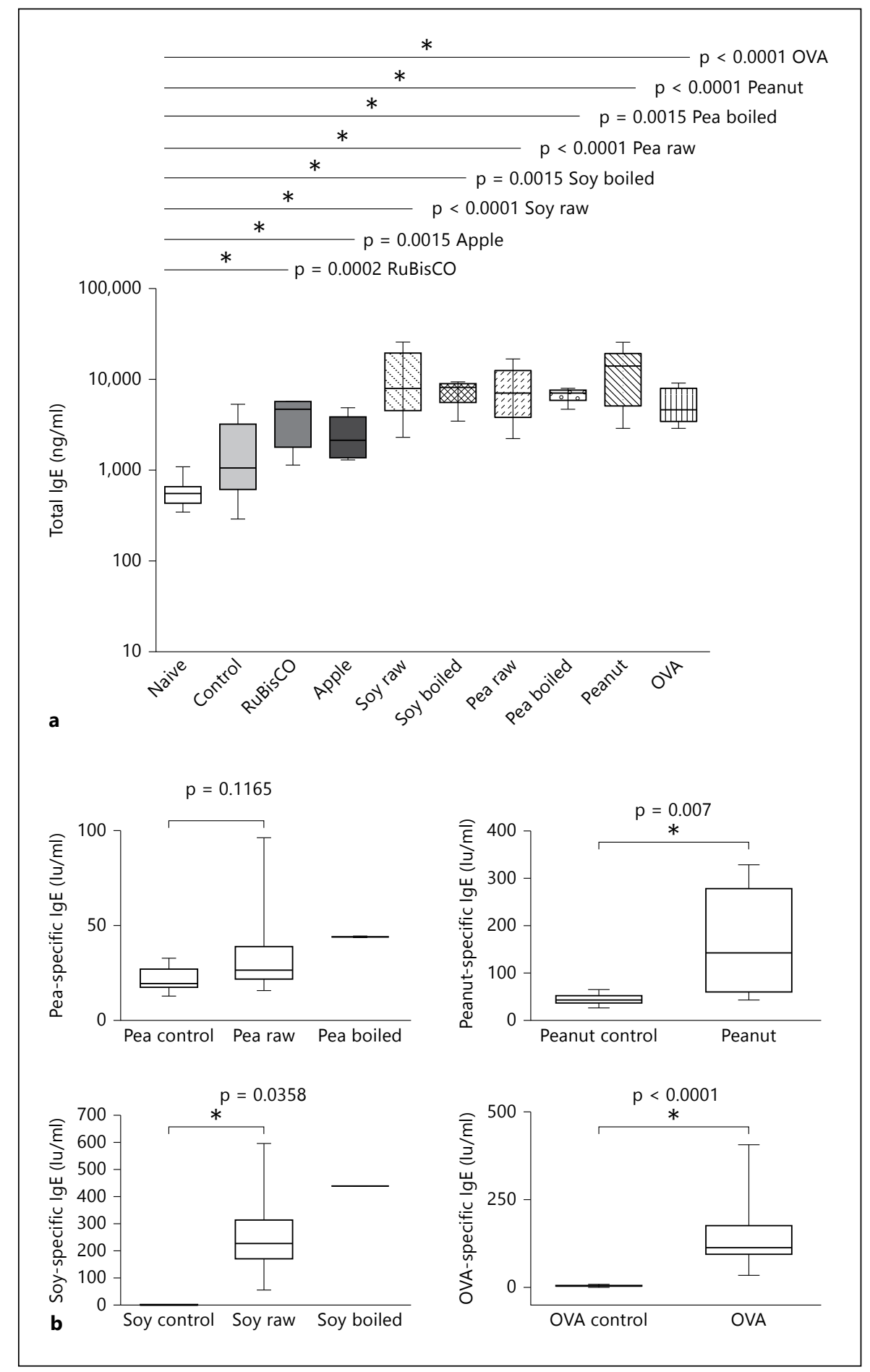

Intestinal Permeability upon Local Allergen Challenge In order to evaluate local functional alterations following oral allergen challenges of sensitized animals, we analyzed changes in intestinal permeability. Urinary excretion of lactulose and mannitol was evaluated after oral uptake of the tracers. The lactulose-mannitol ratio (permeability index) served as a marker for intestinal permeability. Intestinal absorption of lactulose, a disaccharide containing galactose and fructose, occurs predominantly through a paracellular pathway via tight junctions, where- 
Fig. 3. Influence of allergen sensitization and challenge on allergen-specific proliferation. On day 22, spleen mononuclear cells were stimulated for $96 \mathrm{~h}$ with $100 \mu \mathrm{g} /$ $\mathrm{ml}$ of OVA or $100 \mu \mathrm{g} / \mathrm{ml}$ of protein extracts from RuBisCO, apple, pea, soybean and peanut, and $3[\mathrm{H}]$-thymidine was added for the last $18 \mathrm{~h}$.

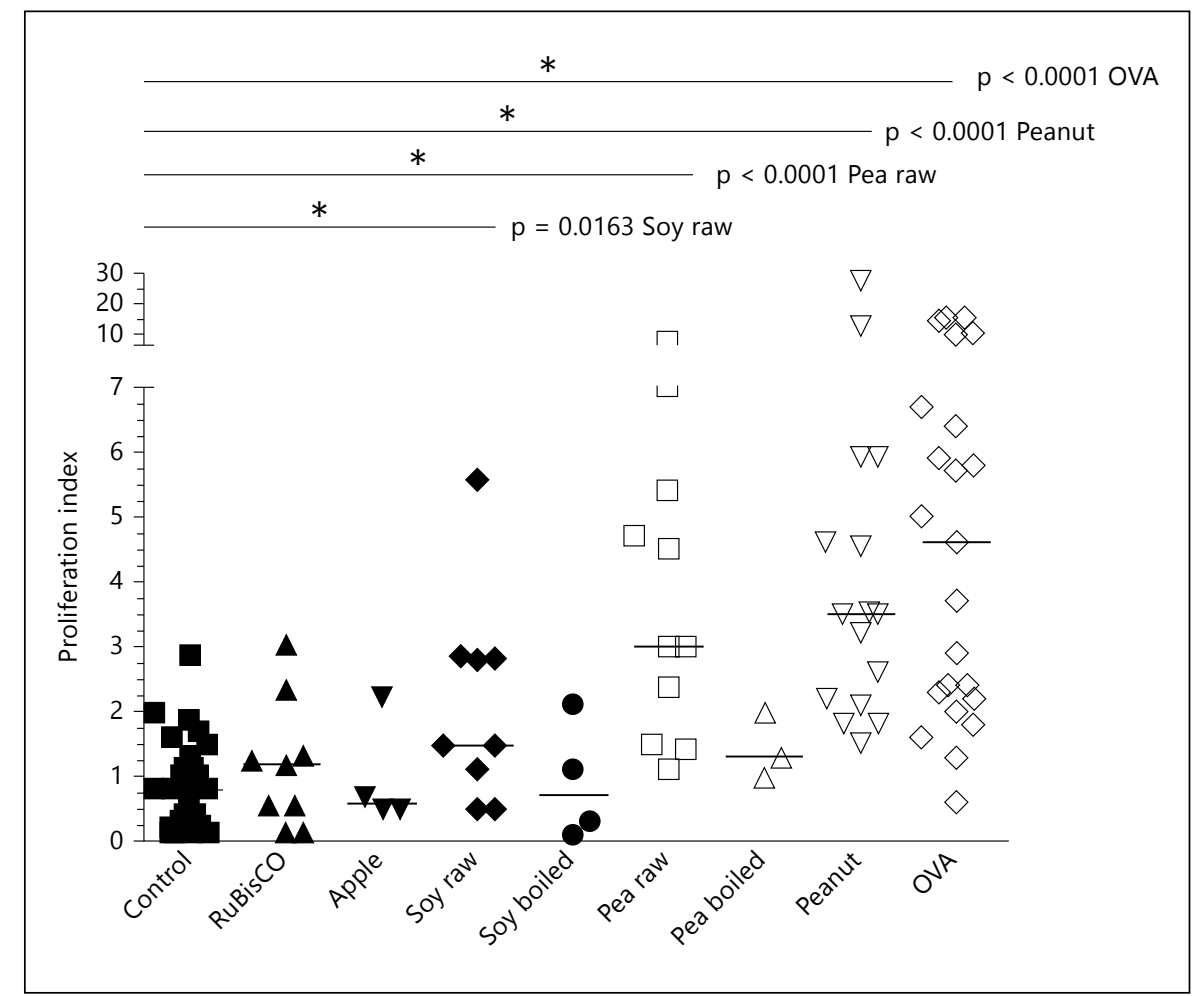

as mannitol is absorbed mainly through an intracellular pathway. Allergen sensitization and repeated oral allergen challenges led to a significant increase in permeability after sensitization with RuBisCO, raw soybean, raw pea, roasted peanut and OVA. Sensitization solely with apple did not lead to a significant change in intestinal permeability (fig. 4). These data confirmed the loss of gut mucosal integrity and elevated intestinal permeability after local allergen challenges in animals sensitized with specific allergens.

\section{Discussion}

We have presented data from a rat model of FA [18] established to quantify and compare the allergenicity of different food allergens. This model was set up in analogy to the well-recognized model of allergic asthma, where a systemic i.p. sensitization with a model allergen is followed by an airway allergen challenge. Accordingly, in the model of FA presented here, the allergen-specific systemic sensitization is followed by an oral allergen challenge. The optimal sensitization protocol, concerning doses of allergen and choice and doses of adjuvant were determined in advance to induce a high and long-lasting
IgE response. We used the purified protein OVA as a reference allergen for comparison with a range of food allergen extracts, since OVA is the most widely applied allergen in animal models. In this way we hoped to take account of the need 'to compare the allergenicity of food extracts versus the purified allergens' [22].

Our final resulting model comprised two hallmark features of FA in patients: allergen-specific immune responses and sensitization and alterations in the intestinal tract upon local allergen challenges. This distinguishes this model from most other existing animal models of FA and allowed testing for allergenicity of different food allergens in a somewhat more 'clinical situation'. The disruption of the intestinal barrier $[23,24]$ may very well be taken as a direct sign of the local allergic response. It indicates a pivotal event in the course of allergic gut inflammation since it allows peptides (epitopes) to cross the intestinal barrier and to stimulate the submucosal immune system, thus enhancing the local production of inflammatory cytokines, mediators and most probably specific IgE antibodies $[25,26]$. The importance of barrier disruption has been highlighted in recent years, especially by publications regarding the loss-of-function variants of the epidermal barrier protein, filaggrin, which display a predisposing factor for atopic eczema [26]. The magni- 
Fig. 4. Influence of allergen sensitization and challenge on intestinal permeability. $\mathrm{BN}$ rats were treated as described in figure 1. Two hours after the 2nd allergen challenge, animals received lactulose/mannitol in PBS p.o. The tracers recovered in the first $8 \mathrm{~h}$ in urine were detected by HPLC. The ratio of recovered lactulose/mannitol (permeability index, PI) served as a marker for intestinal permeability.

Fig. 5. Ranking of the allergenicity. Based upon the systemic and local responses after allergic sensitization and challenges, a scoring system was built. After calculation of the rank sum of the median total IgE levels and proliferative responses (a), as well as of the median total IgE levels, proliferative responses and intestinal permeability (b), a quantification of the allergenicity of the specific allergens by correlation with the specific score was performed and a ranking of the allergenicity of the employed food allergens was depicted. Specific IgE levels were not calculated since levels are allergen specific and therefore not comparable.
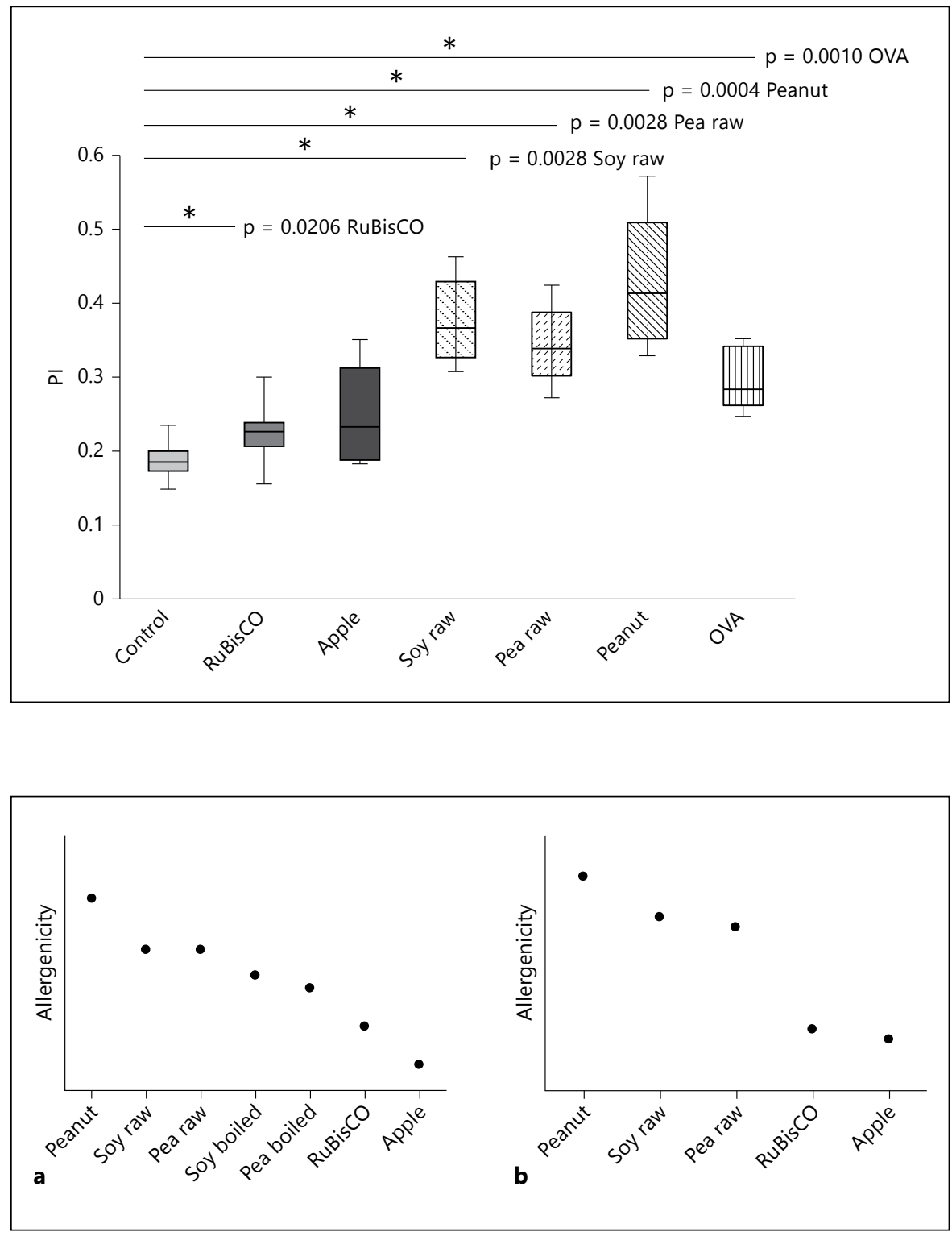

tude of the changes in the intestinal permeability caused by a given allergen is thus a suitable parameter for the (local) allergenicity.

On the basis of the assessment of these two aspects of FA, we compared different common food protein (plant) extracts, all of which are considered to have a different allergenicity, starting with RuBisCO, the most abundant protein on earth and major spinach protein, which is generally accepted as being non-allergic [27]. We further compared the effect of extracts from apple, raw or boiled green garden pea, raw or boiled soybean, and finally roasted peanut, which is considered to be the most aggressive allergenic food.
The systemic and local immune responses induced by allergic sensitization and challenges with apple, raw or boiled green garden pea, raw or boiled soybean, roasted peanut and RuBisCO differed significantly. Based upon the responses, we built a scoring system depicting the allergenic potential of the different allergens. We calculated the rank sum of the median total IgE levels and proliferative responses (fig. 5a) as well as of the median total IgE levels, proliferative responses and intestinal permeability (fig. 5b). We excluded specific IgE levels for this calculation, since the ELISA system is based on comparison of serum levels with allergen-specific controls for each food allergen and utilizes biotinylation of the 
allergen extracts that may differ gradually for the different foods.

The scoring allowed us to build a ranking of the allergenicity of the employed food allergens in our model, with highest values for members of the legume family roasted peanut, raw soy and raw pea - and lowest values for apple and RuBisCO. In regard to clinical symptoms, the rank of intestinal permeability may be more important than the rank of median total IgE levels and proliferative responses. When we overestimated the 'clinical symptom' intestinal permeability by multiplying it by 2 , 5 or 10, the ranking order did not change between peanut, soy and pea.

In humans peanut allergy is accepted as the 'most serious of the hypersensitivity reactions to foods due to its persistence and high risk of severe anaphylaxis' [28]. When taking anaphylaxis as a parameter for severe allergic reactions, epidemiological data on elicitors of anaphylaxis often suggest legumes, especially peanut, to be a food group with all too frequent registered anaphylactic reactions. Other often-reported foods to elicit anaphylaxis are animal-derived food (including hen's egg, cow's milk, fish), tree nuts and fruits [29-31].

Epidemiological data have to be evaluated with care since they are influenced by many factors, such as allergy definitions, study populations, methodologies, ages and eating habits in different countries, etc. This represents one important reason for the development of the FA model presented here.

Pea, soy and peanut comprise up to $70 \%$ of their protein content in the form of $7 \mathrm{~S}$ globulin storage proteins [32]. These belong (next to $11 \mathrm{~S}$ globulins) to the cupin superfamily. $7 \mathrm{~S}$ globulins (vicilin) share extensive immunological cross-reactivity in vitro and show a high sequence homology [32,33]. However, clinically significant cross-reactivity is very rare $[32,33]$. Importantly, the allergenicity in our model was scored much lower after boiling processes for pea and soy, compared with raw protein extracts. These differences were confirmed in immunoblot analysis of the sera of animals sensitized and challenged with either raw or boiled protein extracts (data not shown). Our observation confirms reports by Beyer et al. [8] who showed that methods of frying or boiling peanuts reduced their allergenicity compared with the method of dry roasting. Likewise, it is known that the allergenicity of soybeans is altered after manipulation [34]. Little is known about pea, which in westernized diet is mostly consumed blanched or cooked [32]. Raw pea is ranked rather high in our scoring, prompting one to consider its potential allergenicity in different forms of processed foods, especially in regard to the increasingly popular pea flour in bakery products.

In line with our method, Selgrade et al. [22] have also undertaken a ranking approach. They visualized a 'spectrum of allergenic potency of food extract based on perceived allergenicity in humans' by sketching 12 allergens in an allergic order, including peanut, egg and spinach, among others. Although this assortment lacks the basis of direct assessment, it is reflected to a great extent by our ranking order obtained from a straightforward comparison of different food allergens.

In conclusion, we utilized a rat model of FA to assess the allergenic potential of different employed food proteins and their potency to induce immunological changes on $\mathrm{T}$ and $\mathrm{B}$ cell responses as well as functional alterations. Of course, due to ethical reasons such an analysis is not possible in humans. Even more, the comparability is obscured by different genetic and/or environmental predispositions and backgrounds. We are fully aware that animal models per se have limitations in transferring observed reactions to clinical problems or symptoms in patients. Nevertheless, we believe, that this model provides an interesting tool to assess the potential allergenicity of novel food or food compositions. It may serve as a suitable test system for the allergenicity of unknown or modified allergens and may thus be used as a tool in future safety assessments.

\section{Acknowledgements}

This work was supported by a grant from the Bundesministerium für Bildung und Forschung to E.H. (BMBF 0312216). We thank Christine Seib and Kathrin Borgwald for excellent technical assistance.

\section{References}

1 Sicherer SH, Sampson HA: Food allergy: epidemiology, pathogenesis, diagnosis, and treatment. J Allergy Clin Immunol 2014;133: 291-307.

2 Radauer C, Bublin M, Wagner S, Mari A, Breiteneder $\mathrm{H}$ : Allergens are distributed into few

Different Immunological Responses by

Food Allergens protein families and possess a restricted number of biochemical functions. J Allergy Clin Immunol 2008;121:847-852.

- 3 Rona RJ, Keil T, Summers C, Gislason D, Zuidmeer L, Sodergren E, Sigurdardottir ST, Lindner T, Goldhahn K, Dahlstrom J, Mc-
Bride D, Madsen C: The prevalence of food allergy: a meta-analysis. J Allergy Clin Immunol 2007;120:638-646.

4 Pumphrey RS: Lessons for management of anaphylaxis from a study of fatal reactions. Clin Exp Allergy 2000;30:1144-1150. 
5 Matricardi PM, Bockelbrink A, Beyer K, et al: Primary versus secondary immunoglobulin E sensitization to soy and wheat in the MultiCentre Allergy Study cohort. Clin Exp Allergy 2008;38:493-500.

-6 Savage JH, Kaeding AJ, Matsui EC, Wood RA: The natural history of soy allergy. J Allergy Clin Immunol 2010;125:683-686.

7 De Swert LF, Gadisseur R, Sjölander S, Raes M, Leus J, Van Hoeyveld E: Secondary soy allergy in children with birch pollen allergy may cause both chronic and acute symptoms. Pediatr Allergy Immunol 2012;23:117-123.

$\checkmark 8$ Beyer K, Morrow E, Li XM, Bardina L, Bannon GA, Burks AW, Sampson HA: Effects of cooking methods on peanut allergenicity. J Allergy Clin Immunol 2001;107:1077-1081.

9 Lehrer SB, McClain S: Utility of animal models for predicting human allergenicity. Regul Toxicol Pharmacol 2009;54(suppl 3):S46S51.

10 Peeters KABM, Koppelman SJ, Penninks AH, Lebens A, Bruijnzeel-Koomen CAFM, Hefle SL, Taylor SL, van Hoffen E, Knulst AC: Clinical relevance of sensitization to lupine in peanut-sensitized adults. Allergy 2009;64:549555.

11 Food and Agriculture Organization of the United Nations/World Health Organization (FAO/WHO): Report of a Joint FAO/WHO Expert Consultation on Allergenicity of Foods Derived from Biotechnology. Rome, Food and Agriculture Organization of the United Nations, 2001.

12 Food and Agriculture Organization of the United Nations/World Health Organization (FAO/WHO): Codex Alimentarius Guideline for Conduct of Food Safety Assessments of Foods Derived from Recombinant-DNA Plants; Appendix IV: Annex on Assessment of Possible Allergenicity. Geneva, Codex Alimentarius Commission, 2003, pp 47-60.

-13 EFSA Panel on Genetically Modified Organisms: Guidance for risk assessment of food and feed from genetically modified plants. EFSA J 2011;9:2150. http://www.efsa.europa. eu/en/efsajournal/pub/2150.htm.
14 Bucchini L, Goldman LR: Starlink corn: a risk analysis. Environ Health Perspect 2002;110: 5-13.

15 Finkleman FD: Anaphylaxis: lessons from mouse models. J Allergy Clin Immunol 2007; 120:506-515.

16 Lemon-Mule H, Nowak-Wegryzn A, Berin C, Knight AK: Pathophysiology of food-induced anaphylaxis. Curr Allergy Asthma Rep 2008; 8:201-208.

17 Knippels LM, Penninks AH, Smit JJ, Houben GF: Immune-mediated effects upon oral challenge of ovalbumin-sensitized Brown Norway rats: further characterization of a rat food allergy model. Toxicol Appl Pharmacol 1999; 156:161-169.

18 Ahrens B, Quarcoo D, Buhner S, Matricardi PM, Hamelmann E: Oral administration of bacterial lysates attenuates experimental food allergy. Int Arch Allergy Immunol 2011;156: 196-204.

19 Vieths S, Hoffmann A, Holzhauser T, Müller U, Reindl J, Haustein D: Factors influencing the quality of food extracts for in vitro and in vivo diagnosis. Allergy 1998;53(suppl):65-71.

20 Hirano T, Yamakawa N, Miyajima H, Maeda $\mathrm{K}$, Takai S, Ueda A, Taniguchi O, Hashimoto H, Hirose S, Okumura K, et al: An improved method for the detection of IgE antibody of defined specificity by ELISA using rat monoclonal anti-IgE antibody. J Immunol Methods 1989;119:145-150.

21 Buhner S, Buning C, Genschel J, Kling K, Herrmann D, Dignass A, Kuechler I, Krueger S, Schmidt HH-J, Lochs H: Genetic basis for increased intestinal permeability in families with Crohn's disease: role of CARD15 3020insC mutation? Gut 2006;55:342-347.

22 Selgrade MK, Bowman CC, Ladics GS, Privalle $\mathrm{L}$, Laessig SA: Safety assessment of biotechnology products for potential risk of food allergy: implications of new research. Toxicol Sci 2009;110:31-39.

23 Van Elburg RM, Heymanns HS, De Monchy JG: Effect of disodiumcromoglycate on intestinal permeability changes and clinical response during cow's milk challenge. Pediatr Allergy Immunol 1993;4:79-85.

24 Jalonen T: Identical intestinal permeability changes in children with different clinical manifestations of cow's milk allergy. J Allergy Clin Immunol 1991;88:737-742.
25 Heymann M, Desjeux JF: Cytokine-induced alteration of the epithelial barrier to food antigens in disease. Ann NY Acad Sci 2000;915: 303-311.

26 Hudson TJ: Skin barrier function and allergic risk. Nature Genetics 2006;38:399-400.

$27 \mathrm{Fu}$ TJ, Abbott UR, Hatzos C: Digestibility of food allergens and nonallergenic proteins in simulated gastric fluid and simulated intestinal fluid - a comparative study. J Agric Food Chem 2002;50:7154-7160.

28 Scurlock AM, Burks AW: Peanut allergenicity. Ann Allergy Asthma Immunol 2004; 93(suppl 3):S12-S18.

29 Worm M, Edenharter G, Ruëff F, Scherer K, Pföhler C, Mahler V, Treudler R, Lang R, Nemat K, Koehli A, Niggemann B, Hompes S: Symptom profile and risk factors of anaphylaxis in Central Europe. Allergy 2012;67:691698.

30 Hompes S, Koehli A, Nemat K, Scherer K, Lange L, Rueff F, Rietschel E, Reese T, Szepfalusi Z, Schwerk N, Beyer K, Hawranek T, Niggemann B, Worm M: Provoking allergens and treatment of anaphylaxis in children and adolescents - data from the anaphylaxis registry of German-speaking countries. Pediatr Allergy Immunol 2011;22:568-574.

31 Dinakar C: Anaphylaxis in children: current understanding and key issues in diagnosis and treatment. Curr Allergy Asthma Rep 2012;12:641-649.

32 Kroghsbo S, Bogh KL, Rigby NM, Mills ENC, Rogers A, Madsen CB: Sensitization with $7 \mathrm{~S}$ globulins from peanut, hazelnut, soy or pea induces IgE with different biological activities which are modified by soy tolerance. Int Arch Allergy Immunol 2011;155: 212-224.

33 Wensing M, Knulst AC, Piersma S, O’Kane F, Knol EF, Koppelman SJ: Patients with anaphylaxis to pea can have peanut allergy caused by cross-reactive IgE to vicilin (Ara h 1). J Allergy Clin Immunol 2003;111:420-424.

34 Wilson S, Blaschek K, de Mejia E: Allergenic proteins in soybean: processing and reduction of P34 allergenicity. Nutr Rev 2005;63. 47-58. 